\title{
DETERMINAÇÃO DE CLORETO DE SÓDIO EM ATRIPLEX: UMA ATIVIDADE EXPERIMENTAL PARA OS CURSOS DE CIÊNCIAS BIOLÓGICAS
}

Angela F. Campos*, Cristiano de A. C. Marcelino Jr., Rejane M. Novais Barbosa, Andreza R. Tavares Departamento de Química - Universidade Federal Rural de Pernambuco *relima@hotlink.com.br

\section{Resumo:}

Neste trabalho, uma atividade experimental com a planta Atriplex foi proposta. A prática consistiu na análise do cloreto de sódio presente em uma dada amostra de vegetal. Este experimento foi aplicado aos estudantes do Curso de Ciências Biológicas da disciplina Introdução a Análise Química e discutido por meio de um questionário. Os resultados obtidos mostraram que a aprendizagem dos estudantes com relação ao conceito de reações químicas e sua relação com outros conceitos em Biologia foi satisfatória.

Palavras-chave: Atriplex, atividade experimental, ciências biológicas

\begin{abstract}
:
In this work, an experimental activity with the Atriplex plant was proposed. The practice consisted in the analysis of the sodium chloride present in a given sample of the vegetable. This experiment was applied to students of the Course of Biological Sciences of the discipline Introduction to the Chemical Analysis and discussed by means of a questionnaire. The obtained results showed that the students' learning with relationship to the concept of chemical reactions and its relationship with other concepts in Biology was satisfactory.

Keywords: Atriplex, experimental activity, biological sciences
\end{abstract}




\section{Introdução}

Os resultados de várias pesquisas realizadas nos últimos anos [1], analisando o papel da experimentação no ensino de Ciências e Química, têm reforçado a idéia que a experimentação, por si só, não determina a construção do conhecimento. Os (as) professores (as) têm conhecimento que a realização de experimentos desperta um forte interesse entre os (as) alunos (as) de diferentes níveis de escolaridade, motivando-os (as) e dinamizando a sala de aula. Segundo Borges [2], conceber que alunos (as) diante de evidências observacionais e experimentais descubram ou redescubram leis e princípios científicos, sem levar em consideração suas idéias sobre o mundo em que vivem, trata-se de uma visão tradicional das ciências, empirista, onde a observação dos fenômenos e a realização de experimentos precedem a formulação de teorias. Silva e Zanon [3] reforçam a idéia de Borges e afirmam que esta visão de ciência é amplamente dominante nos contextos escolares.

Pesquisas realizadas por Watson et al. [4] e Barbosa [5] indicam que o uso do experimento somente como elemento comprovador de fatos não leva o (a) aluno (a) a pensar sobre o fenômeno, não garantindo assim a aprendizagem de conceitos científicos. Isto ressalta a importância do papel do (a) professor(a) na substituição de uma postura que utiliza a experimentação apenas de forma demonstrativa, por outra que enfatiza o seu caráter investigativo. Sendo assim, o (a) professor(a) deve atuar como mediador(a) do processo, coordenando as atividades e envolvendo os (as) alunos (as) na formação dos conceitos.

A experimentação é importante na formação de elos entre as concepções espontâneas e os conceitos científicos, propiciando aos (as) alunos(as) oportunidades de confirmar suas idéias ou então reestruturá-las. De acordo com Santos e Schnetzler $[6,7]$, as atividades experimentais são relevantes quando caracterizadas pelo seu papel investigativo e sua função pedagógica em auxiliar o(a) aluno(a) na compreensão dos fenômenos. No ensino de Química, especificamente, a experimentação deve contribuir para a compreensão de conceitos químicos. Mais ainda, as aulas experimentais, de uma forma geral, não necessitam ser realizadas em laboratórios com equipamentos sofisticados, o que inviabilizaria a execução das mesmas.

Em geral, a forma como as atividades experimentais são abordadas deixa muito a desejar, devido a estas serem conduzidas através de roteiros que induzem apenas a comprovação de fatos. Segundo Carvalho e Gil-Pérez [8], "as aulas práticas limitam-se a um processo de verificação, ao estilo de receitas de cozinha, o que não contribui em absoluto para a compreensão da atividade científica". Como também, nem sempre as aulas práticas atendem a necessidade da formação profissional, simulando situações que os(as) alunos(as) enfrentam ou enfrentarão no exercício de suas profissões e não mantêm uma relação entre a prática e os temas centrais discutidos no curso [9]. A não relação entre os conteúdos explorados em sala de aula e o dia-a-dia dos(as) alunos(as) leva-os(as) a não perceberem porque irão utilizar tais conhecimentos.

Alguns desses fatores, comentados anteriormente, têm sido observados freqüentemente com alunos(as) de Ciências Agrárias e Biológicas da Universidade Federal Rural de Pernambuco (UFRPE) que cursam disciplinas curriculares básicas de Química. Verifica-se com grande incidência que, tanto nas aulas teóricas quanto práticas eles(as) se apresentam desmotivados, questionando: o porquê de estudar Química; a utilidade desta matéria para as suas formações profissionais; e o motivo da Química fazer parte da grade curricular de seu curso. Isto gerou a necessidade de se rever as atividades experimentais desses cursos, visando uma melhoria na formação profissional desses(as) alunos(as).

Este trabalho relata o desenvolvimento de uma atividade experimental voltada para o ambiente agrário e sua utilização junto aos(as) alunos(as) dos cursos de Ciências Biológicas. O experimento consistiu na análise qualitativa do cloreto de sódio presente em uma amostra das folhas da Atriplex, uma planta que tem sido alvo de muitas pesquisas no semi-árido nordestino. 


\section{A Planta Atriplex}

O Nordeste do Brasil abrange uma grande área $\left(1.548 .6722 \mathrm{Km}^{2}\right.$ ), dos quais uma parcela significativa (788.064 $\mathrm{Km}^{2}$ ) pertence à região considerada semi-árida. A salinização é uma realidade alarmante no sertão nordestino, conseqüente da ação de fatores naturais, dentre eles, as baixas profundidades dos solos e a rápida evaporação da água devido ao calor. O homem complicou ainda mais essa situação, promovendo a irrigação sem o uso de técnicas apropriadas, aumentando ainda mais a salinidade do solo. Em algumas áreas, a agricultura se tornou quase que impraticável. Por isso, muitas pesquisas têm sido realizadas na intenção de se encontrar soluções para o estabelecimento de culturas vegetais que sobrevivam e sejam produtivas em meio a altíssima salinidade da região $[10,11]$.

Dentre os vegetais adaptados ao semi-árido nordestino têm-se espécies de Atriplex como: $A$. nummalaria, A. halimus, $A$. canescens e $A$. undulata. A Atriplex (figura 1) é uma planta arbustiva de folhas pequenas e verdes de origem australiana, tendo como hábitat o deserto. É conhecida em muitos lugares como "planta sal". Ela vem sendo utilizada na diminuição de impactos ambientais decorrentes do uso de água oriunda do rejeito da dessalinização e de irrigação mal manejada, pois pode absorver entre 1 e 2 toneladas de sais por ano e adapta-se muito bem à terra seca [12].

Os arbustos de Atriplex preferem os climas áridos e semi-áridos. Manifestam ótimo crescimento em regiões com chuvas anuais entre 100 a $500 \mathrm{~mm}$. São altamente resistentes ao estresse hídrico, requerem muita luz e temperaturas diurnas entre $25^{\circ}$ a $40^{\circ} \mathrm{C}$, atingindo melhor crescimento entre as latitudes de $20^{\circ}$ e $50^{\circ}$ norte e sul, respectivamente, e em altitudes que variam desde o nível do mar até mais ou menos $1.500 \mathrm{~m}$.

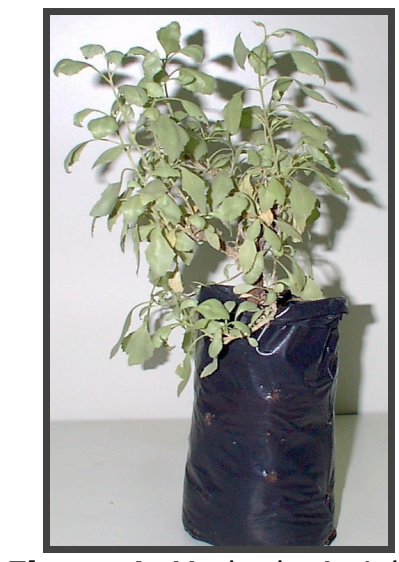

Figura 1. Muda de Atriplex mantida na UFRPE.

As plantas adaptam-se bem em solos secos e pobres em nutrientes, desde os argilosos até os arenosos, salinos, altamente alcalinos e calcários, com pH entre 6 e 9, não sobrevivendo por muito tempo em solos encharcados. Toleram solos poucos profundos, de textura média e com altos níveis de salinidade. Devido ao seu alto valor protéico, as Atriplex são utilizadas como forragem para caprinos, ovinos e bovinos. Os rendimentos variam conforme a espécie da planta usada, tipo de solo, conteúdo de sal no solo, chuvas anuais e tipo de manejo dispensado à cultura. Geralmente, a produção de matéria seca da Atriplex em diversas partes do mundo tem variado entre 3 a 15 toneladas por hectare. Por exemplo, em regiões de solos profundos e precipitações anuais variando entre $200-400 \mathrm{~mm}$, a Atriplex nummalaria e a Atriplex halimus podem produzir de 5 a 10 toneladas de matéria seca por hectare. No entanto, quando a Atriplex é irrigada com água proveniente do rejeito de dessalinização, a média de produção pode variar em torno de 25 toneladas por hectare.

As Atriplex são também usadas, nos processos de dessalinização de solos, na produção de lenha, na medicina e culinária. O processo de dessalinização se inicia quando os arbustos são podados 2 a 3 vezes ao ano, a uma altura de meio metro do solo. A produção de 5 toneladas de matéria seca/ano de Atriplex significa uma extração de $1.000 \mathrm{Kg}$ de sal por hectare/ano. A cultura de Atriplex pode ser usada, também, no combate à erosão e na fixação de dunas $[13,14]$. Estas características fizeram da Atriplex uma fonte importante para a discussão de conceitos químicos que fazem parte dos currículos dos cursos de Ciências Biológicas.

\section{Aspectos Metodológicos}

Inicialmente, os conteúdos de Química das disciplinas básicas (Química Biológica I, Introdução a Análise Química e Análise Química) dos cursos de Ciências Biológicas foram examinados a fim de serem selecionados os conceitos químicos, comuns a estas disciplinas, que poderiam ser abordados com a planta Atriplex. Neste sentido, o conceito de transformações químicas foi escolhido. Em seguida, o experimento foi elaborado e testado no Laboratório de Ensino do Departamento de Química da UFRPE. O procedimento consistiu: (1) retirar algumas folhas da planta e colocá-las em um recipiente com água destilada; (2) triturar estas folhas e filtrar a 
solução resultante; (3) tratar o filtrado com uma solução de nitrato de prata $\left(\mathrm{AgNO}_{3}\right) 0,1 \mathrm{~mol} / \mathrm{L}$; (4) observar o que ocorreu após a adição da solução de nitrato de prata na solução que foi preparada com as folhas da planta. A atividade experimental foi realizada com 31 alunos(as) da disciplina Introdução a Análise Química do Departamento de Química, oferecida ao primeiro período do curso de Bacharelado em Ciências Biológicas da UFRPE.

Também foi elaborado um texto destacando o conceito de reações químicas e a planta Atriplex, que foi trabalhado com os(as) alunos(as) após a experimentação, conjuntamente com algumas questões como: (i) Quê situações do seu cotidiano você considera um fenômeno químico?; (ii) Você acha que a planta Atriplex é uma alternativa ou solução para os lugares áridos ou semiáridos? Por quê? (iii) Você considera a formação de um precipitado uma evidência de uma reação química? Justifique; (iv) Qual a importância do íon cloreto para as plantas em geral? (v) Qual o objetivo deste experimento? (vi) Quais as diferenças que você observa ao comparar esta atividade experimental com outras vivenciadas nessa disciplina?

As questões foram elaboradas visando: verificar o conhecimento dos(as) alunos(as) sobre o conceito de reações químicas, a compreensão deles(as) sobre os resultados obtidos no experimento, a relação que fazem entre os conceitos químicos e biológicos e entre a atividade experimental e seu curso.

\section{Resultados e Discussões}

Analisando as respostas dos(as) alunos(as), observou-se que, $71 \%$ não apresentaram dificuldade em citar situações do cotidiano que eles(as) consideram fenômenos químicos: "Enferrujamento, formação de chuva ácida", "papel queimado, queima do fósforo", "combustão da gasolina". É importante comentar que, dentre ele(as), cerca de $15 \%$ conseguiram relacionar fenômeno químico com Biologia: "Apodrecimento de uma fruta, fotossíntese", "transporte de oxigênio no sangue", "respiração". Entretanto, aproximadamente $16 \%$ dos(as) alunos(as), apesar de relacionarem fenômeno químico a algum conceito de Biologia, também demonstraram em outros exemplos, dificuldades em diferenciar fenômeno físico de fenômeno químico: "Diluição de açúcar em água", "a dissolução do chocolate no leite". Os demais (13\%), em nenhum momento, conseguiram diferenciar fenômeno químico de fenômeno físico: "Aquecer a água para fazer o café", "a tinta que sai de uma roupa escura quando a lavamos", "diluir açúcar no café", dentre outros, foram atribuídos como fenômeno químico.

A dificuldade que os(as) alunos(as) do ensino médio têm em diferenciar uma transformação química de um processo físico, foi constatada por diversos autores [15-21]. No entanto, percebese que os mesmos problemas ainda persistem nos(as) alunos(as) de graduação investigados(as). Por isso, é importante que o(a) professor(a) busque ações didáticas a serem desenvolvidas juntamente com os(as) alunos(as), a fim de que sejam superadas todas as questões que permeiam o conceito de reações químicas.

No que diz respeito ao uso da planta Atriplex como alternativa ou solução para lugares áridos ou semi-áridos, todos(as) os(as) alunos(as) compreenderam a função da planta nestes ambientes: "Seria uma alternativa, pois, elas retiram do solo o sal nele contido. Minimizando assim, a salinidade destes ambientes tão castigados com a seca", "É uma alternativa, pois ela retém sal e tem um alto valor protéico, auxiliando na dieta alimentar dos animais".

A grande maioria dos(as) alunos(as), 99\%, conseguiu associar a formação de um precipitado a um fenômeno químico e compreenderam o objetivo do experimento: "Formou-se um novo composto com coloração esbranquiçada", "Verificar uma reação química através da formação de um precipitado". Durante as discussões dessas questões, foi solicitado aos (as) alunos(as) que escrevessem a equação química (nível representacional do conhecimento químico) referente ao processo químico observado (nível macroscópico). Observou-se que $77 \%$ dos(as) alunos(as) expressaram de forma correta a equação química referente à formação do precipitado obtido no experimento: "NaCl $+\mathrm{AgNO}_{3} \rightarrow \mathrm{AgCl}+\mathrm{NaNO}_{3}$ ". É importante ressaltar, que o conceito de transformação química foi trabalhado com os(as) alunos(as) no nível descritivo e funcional macroscópico, conforme discriminação de níveis do conhecimento químico citado por Jonhstone [22], ou aspecto fenomenológico de acordo com Machado [23]. Os aspectos fenomenológicos do conhecimento químico incluíram tópicos do conhecimento possíveis de visualização concreta, 
como o caso da transformação química ocorrida entre o nitrato de prata e o cloreto de sódio extraído da Atriplex (figura 2).

$\mathrm{Na}$ questão relacionada à importância do cloreto para as plantas, foi verificado que, apesar dos alunos vivenciarem a reação química entre o cloreto presente na Atriplex e o nitrato de prata, em nível macroscópico e representacional, a maioria não conseguiu (74\%) relacionar a função biológica do cloreto nas plantas: "Retenção de água", "formação de sais". Este resultado pode ser atribuído ao fato dos(as) alunos(as) serem do primeiro período do curso de Ciências Biológicas, não tendo ainda estudado conteúdos referentes à nutrição das plantas, especialmente os micronutrientes. Entretanto, esta questão foi levantada com o propósito de abrir uma discussão interdisciplinar e contextualizada, relacionando os conceitos químicos (reações químicas) e biológicos (micronutriente), contribuindo para uma compreensão da importância da Química na formação profissional dos(as) alunos(as).

Com relação às diferenças observadas entre a atividade experimental com Atriplex e outras vivenciadas na disciplina, $46,8 \%$ dos(as) alunos(as) comentaram que o experimento serviu para mostrar um conteúdo de Química (reações químicas) e também, para aproximar a Química da Biologia: "Nas aulas realizadas anteriormente, fizemos experimentos químicos, nesta aula fizemos experimentos químicos

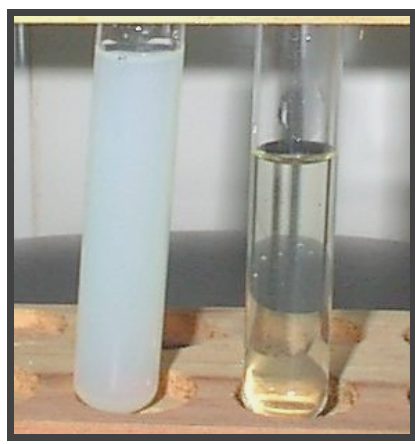

Figura 2. Solução de Atriplex antes (direita) e após (esquerda) o tratamento com solução de nitrato de prata $0,1 \mathrm{~mol} / \mathrm{L}$. relacionados com Biologia".

Foi percebido durante a realização do experimento o interesse dos (as) alunos (as) na atividade, tanto com relação aos conceitos relacionados à Química, quanto às características da planta. Surgiram questões como: "Será que a Atriplex é uma planta adequada para cultivar em praias?", "Que outras plantas também teriam estas características?".

\section{Conclusões}

A planta Atriplex permitiu o estabelecimento de ligações entre o conteúdo de Química, neste caso, reações químicas e outros campos de conhecimento da Biologia. Ela é de fácil trato cultural podendo ser cultivada no próprio campus, conforme ocorre na UFRPE. Os (as) alunos (as), em sua maioria, participaram ativamente das discussões tanto com relação ao conceito em estudo quanto às características da planta.

A abordagem experimental com a Atriplex, por estar relacionada ao cotidiano do aluno(a) do curso de Ciências Biológicas, influenciou no interesse dos(as) alunos(as) pela disciplina e na compreensão dos conceitos científicos envolvidos.

Esta atividade pode ser utilizada por alunos (as) de outros cursos de Ciências Agrárias (Agronomia, Engenharia Florestal, Zootecnia), permitindo-Ihes o desenvolvimento de uma visão interdisciplinar, relacionando a Química com os conteúdos essenciais e específicos de seus referidos cursos.

O experimento proposto é simples e de fácil execução. Os reagentes e vidrarias utilizados na prática são de baixo custo, não havendo necessidade de equipamentos sofisticados.

\section{Referências Bibliográficas}

[1] O. Barberá, P. Valdéz (1996) Trabajo prático lo ensino de Ciências: Uma revisión, Ensenãnza de lãs Ciências. 14 (3), 55.

[2] R. M. R. Borges (1996) Em debate cientificidade e educação em ciências. SE/CECIRS: Porto Alegre.

[3] L. H. A. Silva, L. B. Zanon, in R. P. Schnetzler, e R. M. R Aragão (2000) Ensino de Ciências: fundamentos e abordagens. Editora Ltda: Campinas, 120-153.

[4] R. Watson, T. Prieto, J. Dillon (1995) The effect of practical work on students' understanding of combustion. Journal of Research in Science Teaching, 32(5), 487-502.

[5] R. M. N. Barbosa (1996).Tese de Doutorado. University of East Anglia, Norwich.

[6] W. L. P. Santos, R. P. Schnetzler (1997) Educação em Química: Compromisso com a Cidadania. Ijuí: Unijiú. 
[7] W. L. P. Santos, R. P. Schnetzler (1996) Ensino de Química e Cidadania. Química Nova na Escola, n. 4, 28.

[8] A. M. P. Carvalho, D. Gil-Peréz (1995) Formação de Professores de Ciências. Cortez: São Paulo.

[9] M. I. Rosa, A. C. Negro, C. Martelli (1998) Por que a experimentação é importante no ensino de Química? IX Encontro Nacional de Ensino de Química. Caderno de Resumos e Anais. São Cristóvão, Se.

[10] M. Qadir, D. Steffens, F. Yan, S. Schubert (2003) Land Degradation \& Development. 14 (3), 301.

[11] K. Mahmood, K. Malik, M. Lodhi, K. Sheikh (1994) Environmental Conservation, 21 (3), 236.

[12] Planta Atriplex, uma alternativa para o sertão: http://www.ipa.br/ (consultado em 2002).

[13] Atriplex: http://www.programa-xingo.gov.br/ (consultado em 2001).

[14] J. F. Sutcliffe (1989) As Plantas e os Sais Minerais. São Paulo: EPU. Coleção de Biologia., 33.

[15] M. I. F. P. S. Rosa, R. P. Schnetzler (1998) O conceito de transformação química. Química Nova na Escola. n. 8, 31.

[16] E. F. Mortimer, L. C. Miranda (1995) Concepções dos estudantes sobre reações químicas. Química Nova na Escola. n.2, 23.

[17] R. Driver, in R. Driver, E. Guesne, and A. Tiberghien (1985) Children`s ideas in science. Milton Keynes: Open University Press.

[18] M. Gomez, J. Pozo, and A. Sanz, (1995) Students'ideas on conservation of matter. Science Education. $79(1), 77$.

[19] J. Hesse, and C. Anderson, (1992) Students' conceptions of chemical change. Journal of Research of Science Teaching. 29(3), 277.

[20] B. Anderson (1990) Pupils' conceptions of matter and its transformations (age 12-16). Studies in Science Education. n.18, 53.

[21] B. Anderson (1983) Pupils' explanation of some aspects of chemical reactions, Science Education. 70, n.5, 549.

[22] A. Johnstone, (1982) Macro and Microchemistry. The School Science Review. 64, n. 227, 377.

[23] Machado, A. H., Aula de química: discurso e conhecimento. Ijuí: Editora UNIJUÍ, 1999. 